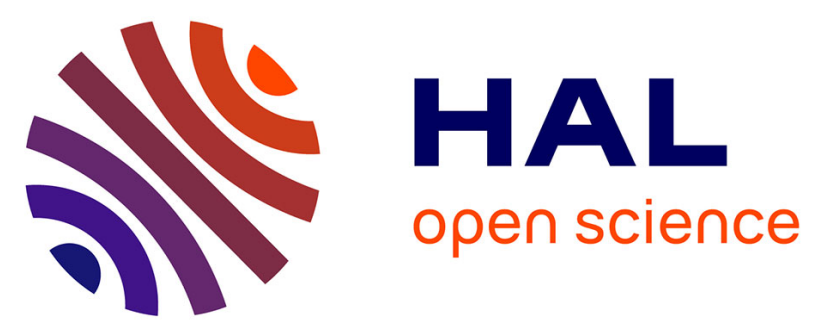

\title{
Influence of the Microstructural Texture of Cast Superalloys on their High-Temperature Oxidation Behaviour
}

\author{
P. Berthod, S Raude, A. S. Renck, C Rapin, Renaud Podor, P Steinmetz
}

\section{- To cite this version:}

P. Berthod, S Raude, A. S. Renck, C Rapin, Renaud Podor, et al.. Influence of the Microstructural Texture of Cast Superalloys on their High-Temperature Oxidation Behaviour. Materials Science Forum, 2004, 461-464, pp.1173 - 1180. 10.4028/www.scientific.net/MSF.461-464.1173 . hal-02275489

\section{HAL Id: hal-02275489 \\ https://hal.science/hal-02275489}

Submitted on 30 Aug 2019

HAL is a multi-disciplinary open access archive for the deposit and dissemination of scientific research documents, whether they are published or not. The documents may come from teaching and research institutions in France or abroad, or from public or private research centers.
L'archive ouverte pluridisciplinaire HAL, est destinée au dépôt et à la diffusion de documents scientifiques de niveau recherche, publiés ou non, émanant des établissements d'enseignement et de recherche français ou étrangers, des laboratoires publics ou privés. 


\title{
Influence of the Microstructural Texture of Cast Superalloys on their High-Temperature Oxidation Behaviour
}

\author{
P. Berthod, S. Raude, A.S. Renck, C. Rapin, R. Podor and P. Steinmetz \\ Laboratoire de Chimie du Solide Minéral (UMR 7555), Faculté des Sciences et Techniques, \\ Université Henri Poincaré Nancy 1, BP 239, 54506 Vandoeuvre-Les-Nancy Cedex, France \\ patrice.berthod@centraliens-lille.org
}

Post-print version of the article: Materials Science Forum (2004) Vols. 461-464, pp.1173-1180

Keywords: High Temperature Oxidation, Cast Superalloys, Grain Size, Dendritic Orientation

\begin{abstract}
The high-temperature oxidation behaviours of Ni base and Co base cast superalloys were studied to determine the effect of different grain sizes and different surface dendritic orientations. These microstructural characteristics were obtained by varying solidification rate and cutting orientation with regard to the external surface. Thermogravimetry tests were run at 1000 and $1100^{\circ} \mathrm{C}$ and parabolic oxidation constants were considered. It appears that oxidation is faster for fine microstructures than for coarser ones for $\mathrm{Ni}$ or Co alloys including tungsten in their chemical composition, while it is the contrary when $\mathrm{W}$ is not present. When the sample surface is mainly parallel to the dendritic network, the oxidation rate is greater than for a surface perpendicular to dendrites, for the studied $\mathrm{Ni}$ alloy. The same phenomenon is observed for the studied Co base alloy at $1100^{\circ} \mathrm{C}$ but the order is inverted at $1000^{\circ} \mathrm{C}$. These different behaviours can be explained by the grain boundary densities and orientations obtained on surface, since they can influence the diffusion of species involved in the oxidation phenomena. It is also possible that the characteristics of the chromia scale, such as grain size and general quality, depend on the microstructural texture of the alloy.
\end{abstract}

\section{Introduction}

The microstructure of metallic alloys resulting from classical foundry practice depends on their chemical composition but also on the solidification conditions. Indeed, local cooling rate and thermal gradient existing during solidification govern, respectively, grain size and dendritic orientation, as well as density and general orientation of grain boundaries. Knowing that the latter act as special diffusion paths for species like $\mathrm{Cr}$ atoms or $\mathrm{O}^{2-}$ anions [1], it can be thought that the kinetics of high-temperature oxidation of superalloys could depend on both microstructural fineness and orientation. These points were studied for several Ni-base and Co-base cast superalloys which are strengthened by intergranular carbides of different types.

\section{Effects of solidification conditions on microstructures}

A metallic cast piece obtained by classical foundry practice usually presents a microstructural evolution from the external surface towards the last point to solidify [2,3,4]. In the nearest neighbourhood of the mould wall, there is a thin zone where solidification begins by the appearance of numerous very small crystals (Fig. 1). Among the latter, only the ones which are the more favourably oriented with regard to the local thermal gradient (generally perpendicular to the mould wall), pursue their growth in the next zone. Thus, after this first zone is formed with a very fine and 
equiaxed microstructure, a columnar zone develops which displays an oriented microstructure. Here columns, or dendrites for $\mathrm{Ni}$ and Co base alloys, are mainly perpendicular to the mould wall, then parallel to the local thermal gradient existing during solidification. The third zone, where solidification finished, contains equiaxed dendrites that have grown in several directions, because of the absence of any very marked gradient. Whatever the zone considered, final crystal or dendrite sizes depend on the solidification rate or on the cooling rate. A low solidification rate leads to a coarser microstructure than does a high one.

After machining, a cast piece can present locally external surfaces with different grain sizes and different orientations with regard to the sub-surface dendritic network.
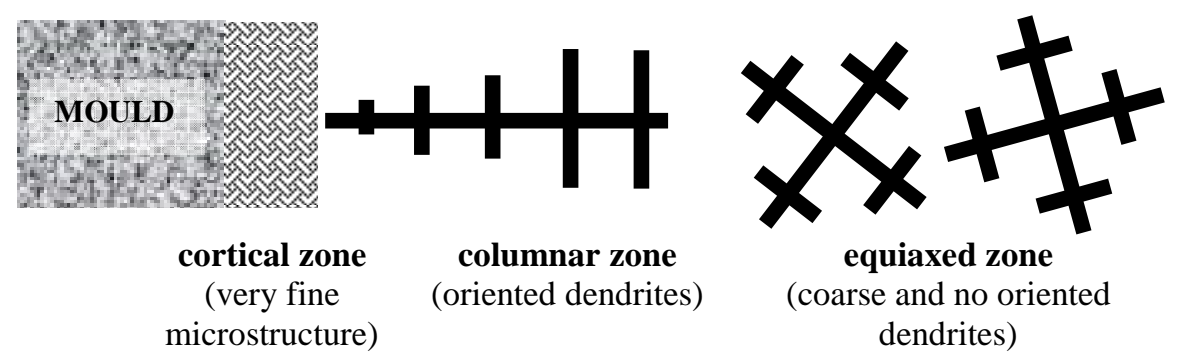

Fig. 1: The three different microstructure zones usually existing from the mould wall in a metallic piece obtained by classical foundry practice

\section{Materials and methods}

General experimental details. Four superalloys were synthesised using an induction furnace under argon gas, and solidified in sand moulds to give cylindrical pieces with a diameter of nearly $30 \mathrm{~mm}$. Chemical compositions of these alloys, a Ni base one and three Co base ones, are given in Table 1. All alloys contained, in the grain boundaries, one or two types of carbides (eutectic $\mathrm{M}_{23} \mathrm{C}_{6}$ and/or MC) known to be very useful for strengthening at high temperatures $[5,6]$.

\begin{tabular}{|c|c|c|c|c|c|c|c|}
\hline weight \% & Co & Ni & Cr & C & W & Ta & Fe \\
\hline Cobalt1 & bal. & 9 & 30 & 0,4 & 6 & 3 & $/$ \\
\hline Cobalt2 & bal. & 9 & 30 & 0,4 & $/$ & 6 & $/$ \\
\hline Cobalt3 & bal. & 9 & 30 & 1,0 & $/$ & 6 & $/$ \\
\hline Nickel1 & $/$ & bal. & 30 & 0,7 & 7,5 & 0 & 7,5 \\
\hline
\end{tabular}

Table 1: Chemical composition of the four cast superalloys studied

Oxidation tests were performed at $1000^{\circ} \mathrm{C}$ and $1100^{\circ} \mathrm{C}$ for 100 hours, using a Setaram TGA92 apparatus and under a flow of industrial air $\left(80 \% \mathrm{~N}_{2}-20 \% \mathrm{O}_{2}\right)$ of about $1,5 \mathrm{~L} / \mathrm{min}$. Samples were parallelepipeds, the dimensions of which were approximately $10 \mathrm{~mm} \times 10 \mathrm{~mm} \times 2 \mathrm{~mm}$. After testing, oxidized samples were covered by a gold layer by cathodic plasma pulverisation, which allowed the external surface to become electrically conductive. Then a sufficiently thick electrolytic nickel coating was deposed in order to mechanically protect the external chromia layer. Thereafter samples were cut, embedded in resin, polished and examined by Scanning Electron Microscope (SEM). 
Other experimental details (grain size). The following procedures were applied to all the alloys to allow the influence of grain size on the oxidation kinetics to be considered. For each alloy a sample for oxidation tests, with a coarse microstructure (characterized by a mean spacing between two secondary dendrite arms $\lambda$ of about $50 \mu \mathrm{m}$ ), was cut from the equiaxed zone of the castings. Elsewhere a part of the latter (about $50 \mathrm{~g}$ ) was remelted in a water-cooled copper crucible in another high induction furnace, in which the alloy solidified with a significantly higher cooling rate. Thus the same alloys were obtained with a finer microstructure $(\lambda \cong 25 \mu \mathrm{m})$. An example of an alloy with a coarse and a fine microstructure is given in Fig. 2.

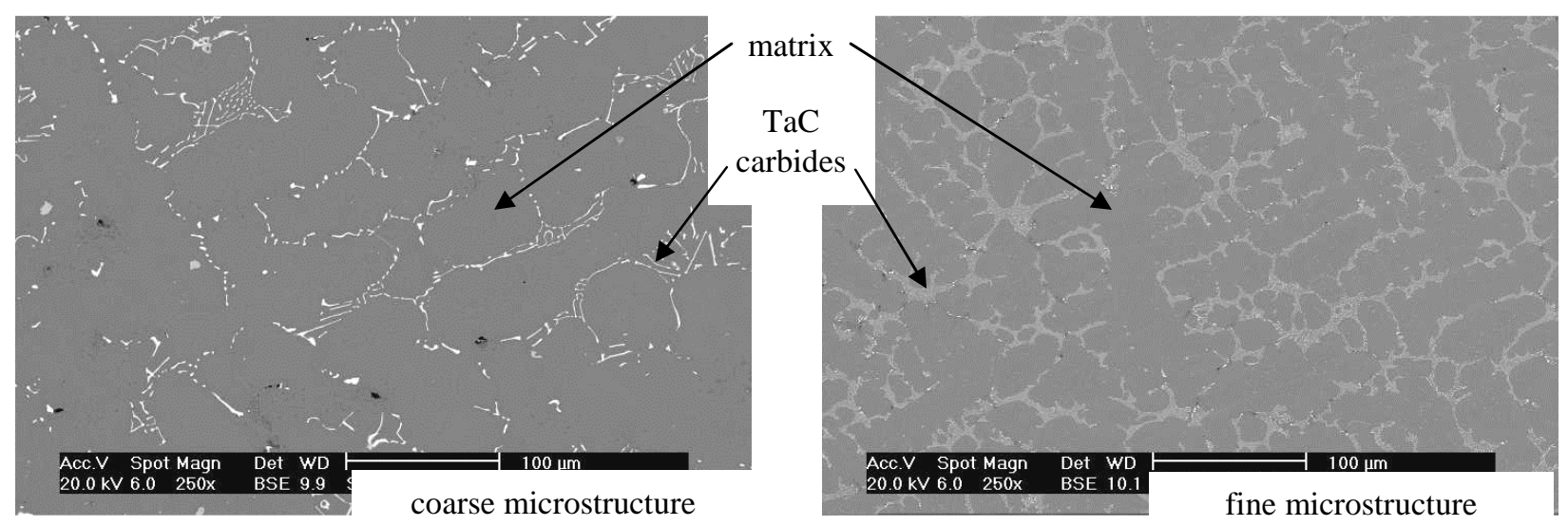

Fig. 2: Example of the two microstructural finenesses in the case of the Cobalt2 alloy

Other experimental details (dendritic orientation). The influence of dendritic orientation on oxidation behaviour was studied only for Cobalt1 and Nickel 1. Two types of samples for oxidation tests were prepared (Fig. 3), with square faces parallel or perpendicular to dendrites. Thus it is possible to obtain an external surface $\left(S=S_{/ /}+S_{\perp}\right)$ which is either mainly parallel to dendrites $\left(S_{/ /}\right.$ $\left.>S_{\perp}\right)$ or mainly perpendicular to dendrites $\left(S_{\perp}>S_{/ /}\right)$. For the same alloy a difference between the two oxidation kinetics for the two types of samples would demonstrate that orientation can have an influence on the oxidation behaviour of the alloy.
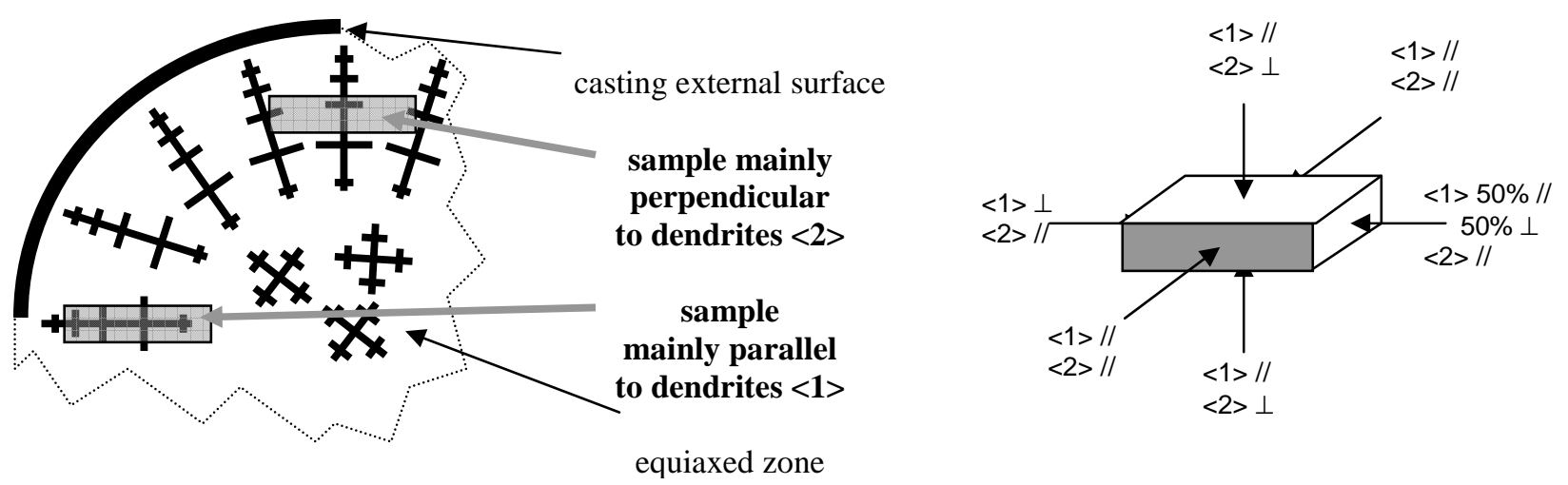

Fig. 3: Cutting modes for samples mainly parallel or mainly perpendicular to dendrites

Moreover, a formula obtained by uncoupling the contributions to the oxidation rate of the parallel part (Eq. 1) and the perpendicular part (Eq. 2) of the external surface can be written (Eq. 3). Then 
the oxidation parabolic constants for $\mathrm{S}_{/ /}\left(\mathrm{Kp}_{/ /}\right)$and $\mathrm{S}_{\perp}\left(\mathrm{Kp}_{\perp}\right)$ appear as the two unknown values of a linear equation (Eq. 4) in which also the measured total constant appears.

$$
\begin{aligned}
& \frac{\Delta \mathrm{m}_{/ /}}{\mathrm{S}_{/ /}}(\mathrm{t})=\sqrt{2 \cdot \mathrm{Kp}_{/ /}} \cdot \mathrm{t}^{\frac{1}{2}} \quad(1) \quad \frac{\Delta \mathrm{m}_{\perp}}{\mathrm{S}_{\perp}}(\mathrm{t})=\sqrt{2 \cdot \mathrm{Kp}_{\perp}} \cdot \mathrm{t}^{\frac{1}{2}} \\
& \frac{\Delta \mathrm{m}}{\mathrm{S}}(\mathrm{t})=\frac{\Delta \mathrm{m}_{/ /}(\mathrm{t})+\Delta \mathrm{m}_{\perp}(\mathrm{t})}{\mathrm{S}_{/ /}+\mathrm{S}_{\perp}}=\frac{\mathrm{S}_{/ /}}{\mathrm{S}_{/ /}+\mathrm{S}_{\perp}} \sqrt{2 \cdot \mathrm{Kp} / /} \cdot \sqrt{\mathrm{t}}+\frac{\mathrm{S}_{\perp}}{\mathrm{S}_{/ /}+\mathrm{S}_{\perp}} \sqrt{2 \cdot \mathrm{Kp}_{\perp}} \cdot \sqrt{\mathrm{t}} \\
& \frac{\mathrm{S}_{/ /}}{\mathrm{S}} \sqrt{2 \cdot \mathrm{Kp}_{/ /}}+\frac{\mathrm{S}_{\perp}}{\mathrm{S}} \sqrt{2 \cdot \mathrm{Kp}_{\perp}}=\sqrt{2 \cdot \mathrm{Kp}}
\end{aligned}
$$

Solving the two linear equations (Eq. 4) written for two samples of the same alloy oxidized at the same temperature, leads to values of both $\mathrm{Kp}_{/ /}$and $\mathrm{Kp}_{\perp}$.

\section{Results}

Effects of alloy grain size. Thermogravimetry results show that high-temperature oxidation kinetics are obviously dependant on the microstructural fineness. Indeed, for the same alloy, the mass gain curves obtained for the coarse and fine microstructures are different, as shown by Fig. 4.
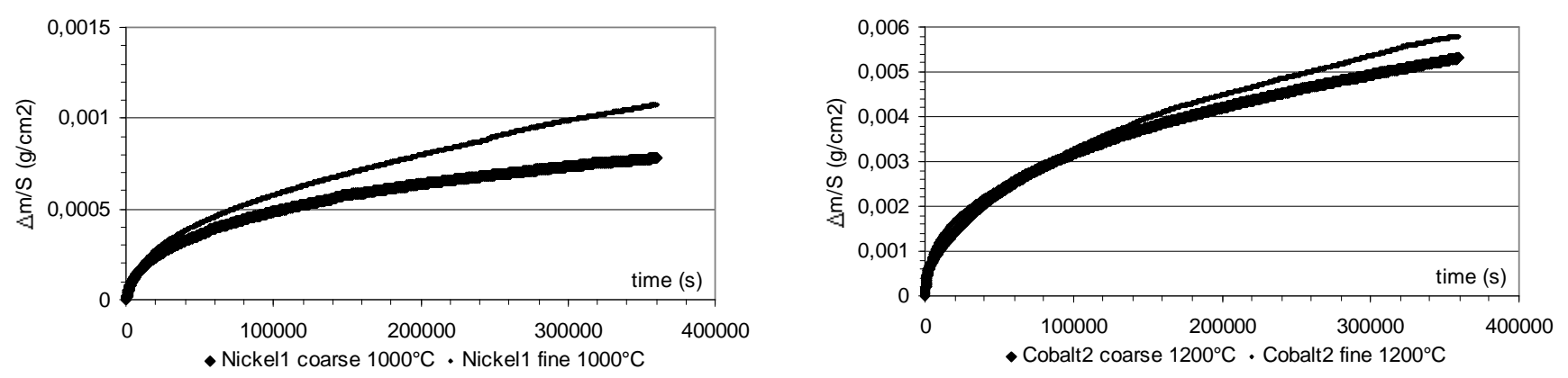

Fig. 4: Some examples of mass gain curves for two different grain sizes of the same alloy (on the left: case of Nickel1 at $1000^{\circ} \mathrm{C}$, on the right: case of Cobalt 1 at $1200^{\circ} \mathrm{C}$ )

Table 2 presents all the oxidation parabolic constants determined from the obtained curves. These values also show that oxidation rate varies with grain size but not always in the same way. Differences between "coarse" and "fine" were very marked for 3 over the 6 cases, since the parabolic constants ratio were higher than 2 or lower than 0.5 . The difference depended on the alloy, possibly on its chemical composition. For instance, the alloys showing a higher oxidation rate for a fine structure than for a coarser one all contained tungsten (Nickel1 and Cobalt1), while the opposite was found for the others (Cobalt2 and Cobalt3). For the only alloy tested for several temperatures (Cobalt2), the parabolic constants ratio increased with temperature, from values lower than 1 to values higher than 1 . Thus, a fine Cobalt 1 oxidized faster than a coarse Cobalt 1 at relatively low temperatures $\left(<1000^{\circ} \mathrm{C}\right)$, as fast as the coarse one at $1100^{\circ} \mathrm{C}$, and slower than the coarse one at higher temperatures $\left(>1200^{\circ} \mathrm{C}\right)$. Oxidation and/or diffusion phenomena seem to be a little different, since activation energies (Fig. 5) were $185 \mathrm{~kJ} / \mathrm{mol}$ for the coarse microstructure and $253 \mathrm{~kJ} / \mathrm{mol}$ for the fine one. The three points in Fig. 5 were not really aligned, doubtless because of a high volatilization rate of chromia at $1200^{\circ} \mathrm{C}$ (oxidised into gaseous $\mathrm{CrO}_{3}$ ) which reduces the 
measured parabolic constant. If only the two points corresponding to the two lowest temperatures are considered, the activation energies become higher (Table 2).

Another interesting observation is that a dependence of the oxidation rate on the density of carbides previously observed for this alloys family [7], was observed here for the coarse microstructures but not for fine microstructures. Indeed, $\mathrm{Kp}_{\text {coarse }}$ at $1000^{\circ} \mathrm{C}$ raised with $\mathrm{C}$ content, whatever the nature of the carbides, while all parabolic constants at $1000^{\circ} \mathrm{C}$ were similar when microstructures were finer (all values are near $1.510^{12} \cdot \mathrm{g}^{2} \cdot \mathrm{cm}^{-4} \cdot \mathrm{s}^{-1}$ ).

\begin{tabular}{|c|c|c|c|c|c|c|c|}
\hline $10^{12} \cdot \mathrm{Kp}$ & \multicolumn{2}{|c|}{ microstructure } & \multirow{2}{*}{$\begin{array}{c}\frac{\mathrm{Kp}_{\text {fine }}}{\mathrm{Kp} \text { coarse }} \\
\text { ratio } \\
\end{array}$} & \multirow{2}{*}{\multicolumn{2}{|c|}{$\begin{array}{c}\text { Activation } \\
\text { energy } \\
(\mathrm{kJ} . m o l-1)\end{array}$}} & \multirow{2}{*}{\multicolumn{2}{|c|}{$\begin{array}{l}\text { Activation } \\
\text { energy } \\
(\mathrm{kJ} . \mathrm{mol}-1)\end{array}$}} \\
\hline $\mathrm{g}^{2} \cdot \mathrm{cm}^{-4} \cdot \mathrm{s}^{-1}$ & $\begin{array}{l}\text { coarse } \\
\text { Kp }\end{array}$ & $\begin{array}{c}\text { fine } \\
\mathrm{Kp}_{\text {fine }}\end{array}$ & & & & & \\
\hline Nickel1* $\left(1000^{\circ} \mathrm{C}\right)$ & 0.57 & 1.55 & 2.72 & & & & \\
\hline Cobalt1 $^{*}\left(1000^{\circ} \mathrm{C}\right)$ & 1.15 & 1.44 & 1.25 & tempe & tures & temp & $\begin{array}{l}\text { lowest } \\
\text { atures }\end{array}$ \\
\hline Cobalt $2\left(1000^{\circ} \mathrm{C}\right)$ & 2.69 & 1.52 & 0.53 & coarse & fine & coarse & fine \\
\hline Cobalt $2\left(1100^{\circ} \mathrm{C}\right)$ & 18.7 & 15.3 & 0.82 & 185 & 253 & 282 & 336 \\
\hline Cobalt $2\left(1200^{\circ} \mathrm{C}\right)$ & 28.0 & 37.8 & 1.35 & & & & \\
\hline Cobalt3 $\left(1000^{\circ} \mathrm{C}\right)$ & 3.46 & 1.39 & 0.41 & & OII & s tungst & \\
\hline
\end{tabular}

Table 2: Values of the oxidation parabolic constants obtained for all tests and activation energies for the two grain sizes (Cobalt2 alloy)

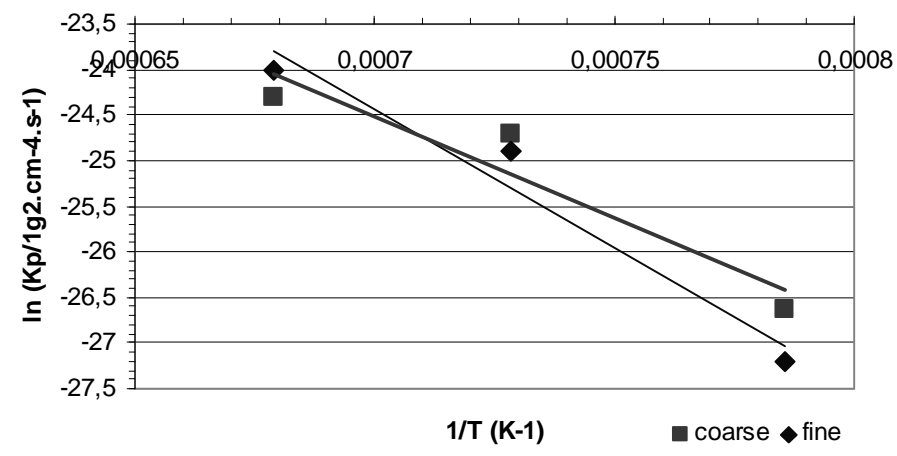

Fig. 5: $\ln (\mathrm{Kp})$ versus the inverse of temperature in Kelvin for the Cobalt2 alloy; determination of the activation energy associated to the coarse and the fine microstructures

Microscope examinations were performed on the samples after special metallographical preparation. Even if the external $\mathrm{Cr}_{2} \mathrm{O}_{3}$ scales were always mainly lost during cooling after thermogravimetry tests, some parts of this layer remained on the sample surfaces so that it was possible to estimate the chromia thickness. The order of the chromia thickness on the alloys was in most cases the same as for the parabolic constants. The depth of internal oxidation $\left(\mathrm{Cr}_{2} \mathrm{O}_{3}\right.$ and/or $\mathrm{CrTaO}_{4}$ depending on the alloy) was also assessed and it appeared that there was no differences between the two microstructural finenesses for the same alloy $\left(20 \mu \mathrm{m}\right.$ for all alloys at $\left.1000^{\circ} \mathrm{C}\right)$.

Cobalt 2 was also tested at two higher temperatures, 1100 and $1200^{\circ} \mathrm{C}$. The order of the parabolic constant values and of the assessed chromia thicknesses were the same as at the lower temperature. Internal oxidation increased with temperature, from about $20 \mu \mathrm{m}$ (coarse or fine) at $1000^{\circ} \mathrm{C}$ to 30 (fine) or $50 \mu \mathrm{m}$ (coarse) at $1200^{\circ} \mathrm{C}$. A zone having lost its initial intergranular carbides began to be visible at $1100^{\circ} \mathrm{C}$ and became deeper from the external surface at $1200^{\circ} \mathrm{C}$, about 80 (coarse) or $90 \mu \mathrm{m}$ (fine), as illustrated by Fig. 6.

Thus, with increasing temperature, oxidation rate and the carbide-free band growth rate increased and were higher for a fine microstructure than for a coarse one, while the internal oxidation depth 
also increased but with an inverted order between coarse and fine. As was observed earlier [8], this tendency remained at $1300^{\circ} \mathrm{C}$ since the depth of the carbide-free zone was, after 20 hours, nearly $120 \mu \mathrm{m}$ for a coarse microstructure and the double for a fine one. At these high temperatures, tantalum diffuses towards the oxidation front from the zone containing tantalum carbides. Tantalum oxides formed a discontinuous band in the alloy just under the chromia layer.

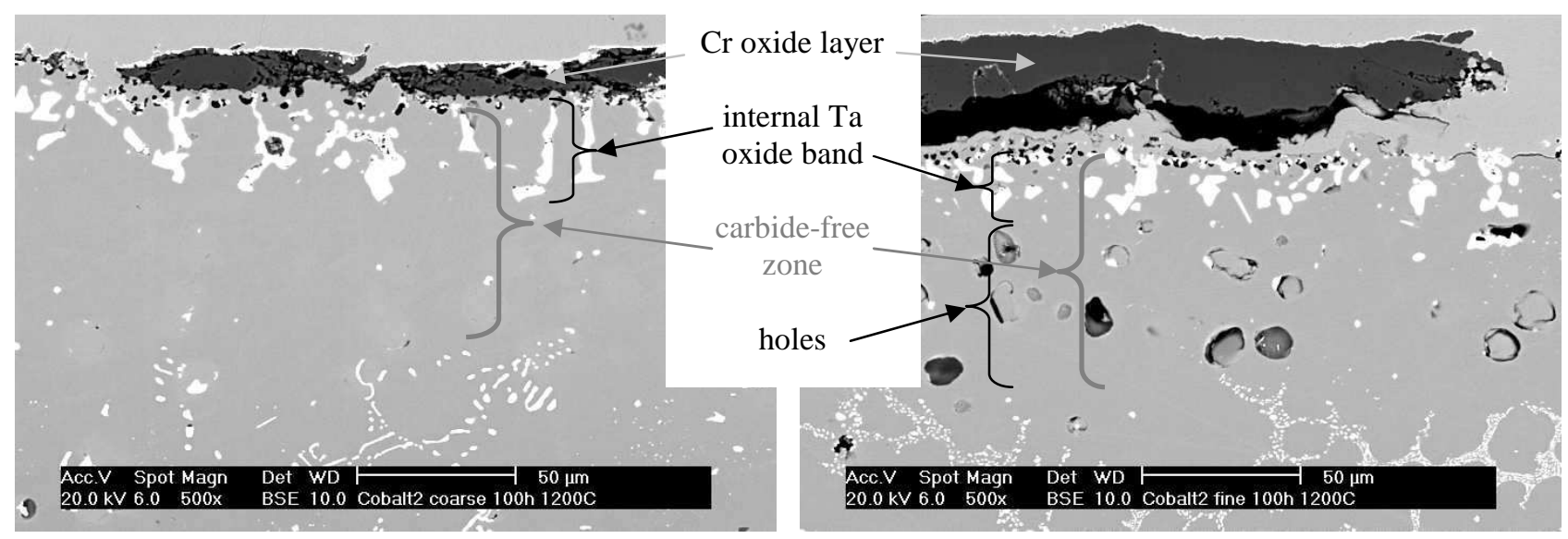

Fig. 6: Depth of the carbideless zone for Cobalt 2 oxidized at $1200^{\circ} \mathrm{C}$ for 100 hours in the cases of a coarse microstructure (on the left) and of a fine one (on the right)

Effects of dendritic orientation. The mass gain curves suggest that oxidation rate was more or less dependant on the dendritic orientation. Fig. 7 displays curves for Nickell at $1000^{\circ} \mathrm{C}$ which are sensibly different from one another, the oxidation rate being higher for the sample parallel to dendrites than for the perpendicular one. On the contrary, the kinetics were almost the same for Cobalt 1 at $1000^{\circ} \mathrm{C}$, with a tendency for a lightly slower oxidation rate for the sample mainly parallel to dendrites than for the perpendicular one. These observations are reflected in the parabolic constants values in Table 3, and amplified after uncoupling of the two contributions. Comparing the behaviour at 1000 and $1100^{\circ} \mathrm{C}$, it appears that oxidation rate of Nickel1 was higher for samples mainly parallel to dendrites than for perpendicular ones, with a ratio of 10 at $1000^{\circ} \mathrm{C}$ and of 4 at $1100^{\circ} \mathrm{C}$ on the parabolic constants, and a ratio of 3 at $1000^{\circ} \mathrm{C}$ and of 2 at $1100^{\circ} \mathrm{C}$ for the rate of mass gain at each time. Similar results were reported earlier for simple Ni-30Cr-0.8C (\%wt) alloys [9] but with less marked differences. For Cobalt1, oxidation rate was lightly higher for the sample mainly perpendicular to dendrites than for the parallel one at $1000^{\circ} \mathrm{C}$, and the difference increased with temperature.
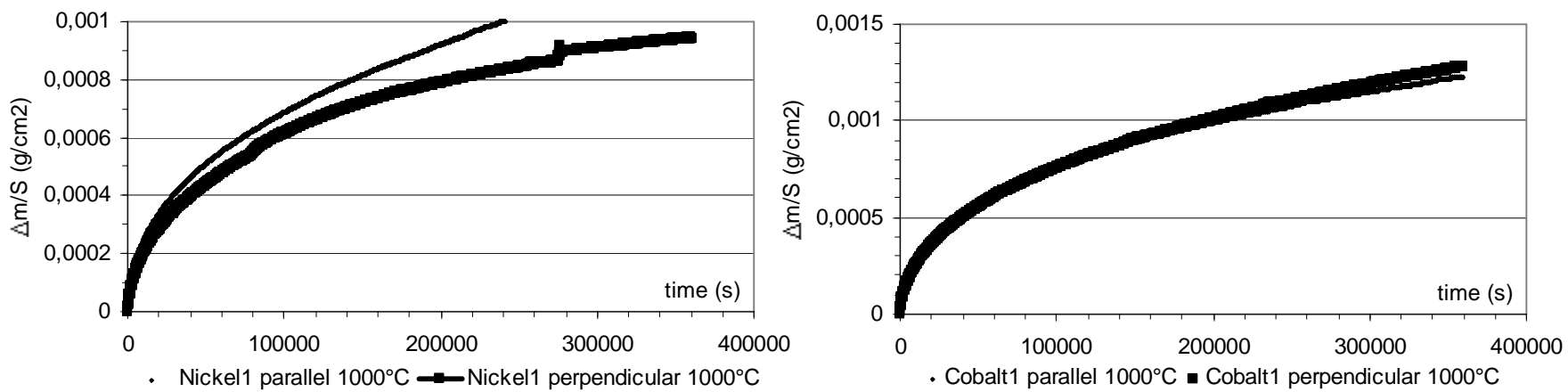

Fig. 7: Some examples of mass gain curves obtained for the two dendritic orientations 


\begin{tabular}{|c|c|c|c|c|c|}
\hline \multicolumn{6}{|c|}{ values of $10^{12} \cdot \mathrm{Kp}$ in $\mathrm{g}^{2} \cdot \mathrm{cm}^{-4} \cdot \mathrm{s}^{-1}$} \\
\hline \multirow[t]{2}{*}{$1000^{\circ} \mathrm{C}$} & $\mathrm{Kp}_{\text {plaq } / /}$ & $\mathrm{Kp}_{/ /}$ & \multirow[t]{2}{*}{$1100^{\circ} \mathrm{C}$} & $\mathrm{Kp}_{\text {plaq } / /}$ & $\mathrm{Kp}_{/ /}$ \\
\hline & $K p_{\text {plaq } \perp}$ & $\mathrm{Kp}_{\perp}$ & & $\mathrm{Kp}_{\text {plaq } \perp}$ & $\mathrm{Kp}_{\perp}$ \\
\hline \multirow[t]{2}{*}{ Nickel1 } & 1,71 & 2,30 & \multirow[t]{2}{*}{ Nickel1 } & 5,57 & 6,28 \\
\hline & 0,63 & 0,19 & & 2,67 & 1,51 \\
\hline \multirow[t]{2}{*}{ Cobalt1 } & 1,32 & 1,22 & \multirow[t]{2}{*}{ Cobalt1 } & 7,14 & 5,76 \\
\hline & 1,69 & 1,90 & & 10,38 & 14,32 \\
\hline
\end{tabular}

Table 3: Values of the global parabolic constants and of the uncoupled ones for the two alloys

The external chromia thicknesses were of the same order as the uncoupled parabolic constants for Nickel1, with chromia scales thicker for the parallel surfaces than for the perpendicular ones. On the contrary there was no real difference of chromia scale thicknesses between the two orientations for Cobalt1. For the two alloys the depth of internal oxidation increased with temperature (it doubled between 1000 and $1100^{\circ} \mathrm{C}$ ) and internal oxidation was more extended for Cobalt1 than for Nickel1. For Nickel1 the internal oxidation depth did not depend on the dendritic orientation (less than $20 \mu \mathrm{m}$ for $1000^{\circ} \mathrm{C}$ and about $35 \mu \mathrm{m}$ for $1100^{\circ} \mathrm{C}$ ). On the contrary the internal oxidation depth was greater for the perpendicular orientation $\left(30\right.$ at $1000^{\circ} \mathrm{C}$ and $65 \mu \mathrm{m}$ at $\left.1100^{\circ} \mathrm{C}\right)$ than for the parallel one $\left(20\right.$ at $1000^{\circ} \mathrm{C}$ and $40 \mu \mathrm{m}$ at $1100^{\circ} \mathrm{C}$ ). The differences in oxidation rate observed for the two orientations appeared to be directly associated to the chromia growth rate in the case of Nickel1, while it was more related to the internal oxidation for Cobalt1.
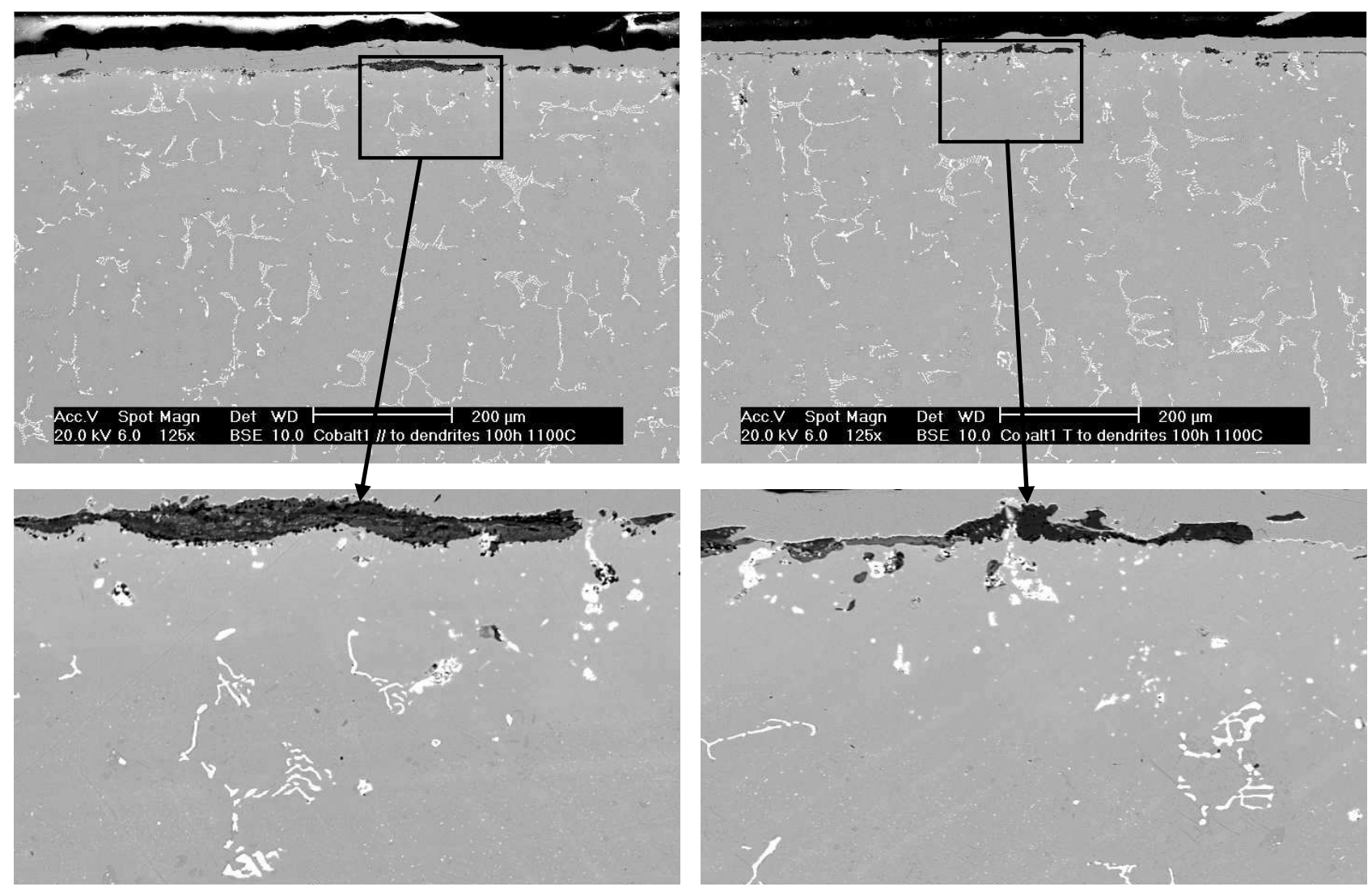

Fig. 8: View of the two orientations of dendrites with regard to the surface (Cobalt1) and surface state after oxidation at $1100^{\circ} \mathrm{C}$ for 100 hours 


\section{Discussion}

These results, taken together with earlier data [10], demonstrate that both grain size and dendritic orientation can affect the high-temperature oxidation rate. This influence remains to be fully explained ; however, a first hypothesis is presented here.

The effect of alloy grain size on oxidation rate exists, but there is also a dependance on chemical composition, more precisely, on the presence of tungsten in the alloy. A fine microstructure leads to a high density of grain boundaries emerging at the surface. In that case, chromium can diffuse more rapidly towards the oxidation front, and this facilitates the rapid initial formation of the protective chromia scale and an efficient supply thereafter. Thus the chromia scale can be of a higher quality, and more protective. However, if the alloy contains tungsten, which participates in the formation of interdendritic carbides, oxidation of these leads to the formation of $\mathrm{WO}_{3}$ gaseous oxides which can disturb the chromia growth and its protective quality. Thus, a small grain size promotes a high density of grain boundaries, which can lead to more severe deterioration of the chromia scale. Elsewhere, it is possible that the fine grain size of the alloy promotes the development of an external chromia layer with a high density of grain boundaries in the oxide itself. Its conductivity for ions or content of point defects may be higher, which may increase the oxidation rate.

Dendrite orientation can have similar effects on the characteristics of the external chromia scale, and therefore on its protection efficiency. Since grain boundaries are often more conductive than the alloy matrix, it is likely that diffusion can be easier for the perpendicular orientation than for the parallel one, with consequences on the formation of the protective chromia scale and supply of $\mathrm{Cr}$ (Nickel1), and also on the internal oxidation progress (Cobalt1).

\section{Conclusion}

The chemical composition is not the only alloy parameter having some influence of the hightemperature oxidation behaviour of carbide-strengthened cast superalloys. Indeed, it appeared here that both grain size and dendritic orientation must be taken into account, for example, when comparative oxidation tests are made in order to optimise the chemical composition of an alloy for improving its oxidation behaviour. But this influence, which seems also to depend on other chemical or microstructural parameters, is difficult to define and more work remains to be done for better understanding of the involved phenomena. First, tests at other temperatures are needed on all alloys in order to define the activation energies. Second, microprobe contents profiles and texture analysis of the chromia layer are required to understand the diffusion phenomena and their differences when grain size or dendritic orientation vary.

\section{References}

[1] P. Kofstad: High Temperature Corrosion (Elsevier 1988)

[2] W. Kurz, D.J. Fisher: Fundamentals of solidification (Trans. Tech Publications, 1989)

[3] G. Lesoult: M59 (Techniques de l'Ingénieur 1989)

[4] G. Lesoult: M58 (Techniques de l'Ingénieur 1986)

[5] E.F. Bradley: Superalloys : A technical guide (ASM International 1988)

[6] C.T. Sims and W.C. Hagel: The superalloys (John Wiley \& Sons 1972

[7] J. Di Martino: PhD Thesis (Université de Nancy 1, 2002)

[8] J. Di Martino, S. Michon, L. Aranda, P. Berthod, R. Podor and C. Rapin: Annales de Chimie - Science des Matériaux 28 Suppl.1 (2003), S231-S238

[9] P. Berthod, S. Noël, C. Rapin, R. Podor and P. Steinmetz: poster presented at Gordon Research Conference "High Temperature Corrosion" (New London NH 2003)

[10] P. Berthod, S. Raude, A.S. Renck, C. Rapin and R. Podor: article submitted to Revue de Métallurgie-SGM 